
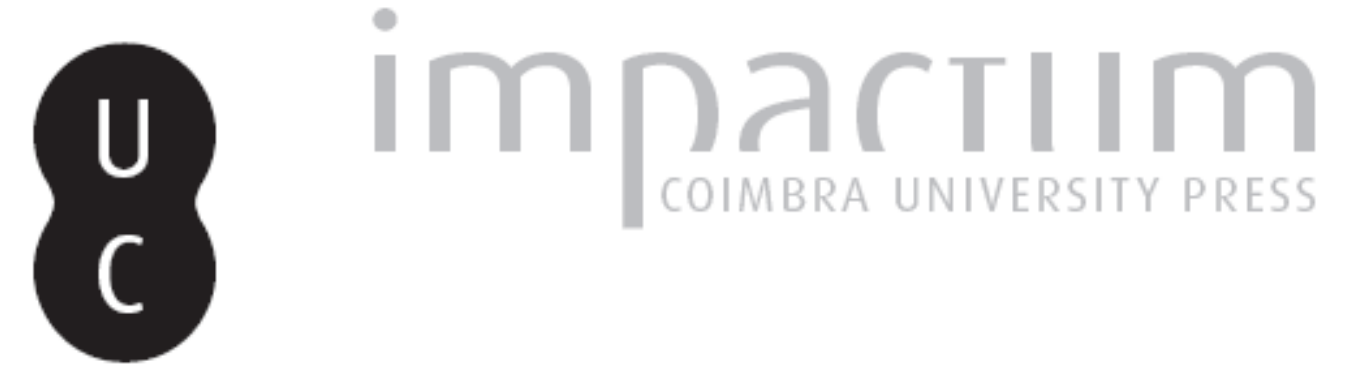

\title{
Um exemplo do reaproveitamento de materiais arqueológicos de Miróbriga: a reconstrução do pelourinho de Santiago do Cacém em 1732
}

\author{
Autor(es): $\quad$ Falcão, José António
}

Publicado por: Imprensa da Universidade de Coimbra

URL

persistente:

URI:http://hdl.handle.net/10316.2/45500

DOI:

DOI:https://dx.doi.org/10.14195/1647-8657_32_33_26

Accessed : $\quad$ 26-Apr-2023 14:49:38

A navegação consulta e descarregamento dos títulos inseridos nas Bibliotecas Digitais UC Digitalis, UC Pombalina e UC Impactum, pressupõem a aceitação plena e sem reservas dos Termos e Condições de Uso destas Bibliotecas Digitais, disponíveis em https://digitalis.uc.pt/pt-pt/termos.

Conforme exposto nos referidos Termos e Condições de Uso, o descarregamento de títulos de acesso restrito requer uma licença válida de autorização devendo o utilizador aceder ao(s) documento(s) a partir de um endereço de IP da instituição detentora da supramencionada licença.

Ao utilizador é apenas permitido o descarregamento para uso pessoal, pelo que o emprego do(s) título(s) descarregado(s) para outro fim, designadamente comercial, carece de autorização do respetivo autor ou editor da obra.

Na medida em que todas as obras da UC Digitalis se encontram protegidas pelo Código do Direito de Autor e Direitos Conexos e demais legislação aplicável, toda a cópia, parcial ou total, deste documento, nos casos em que é legalmente admitida, deverá conter ou fazer-se acompanhar por este aviso.

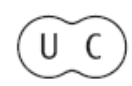




\section{UNIVERSIDADE DE COIMBRA \\ FACULDADE DE LETRAS}

\section{CONIMBRIGA}

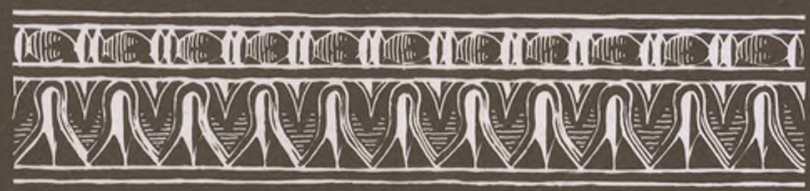

VOLUMES XXXII-XXXIII-1993/94 


\section{JosÉ ANTÓNIO FALCÃO}

Director do Departamento do Património Histórico e Artístico da Diocese de Beja

UM EXEMPLO DO REAPRO VEIT AMENTO DE MATERIAIS

ARQUEOLÓGICOS DE MIRÓBRIGA:

A RECONSTRUÇÃO DO PELOURINHO DE SANTIAGO DO CACÉM

EM 1732

"Conimbriga" XXXII-XXXIII (1993-1994), p. 403-415

RESUMO: A Câmara de Santiago do Cacém decidiu reedificar, em 1732, o

pelourinho antigo da vila, utilizando para o efeito o fuste de urna coluna romana localizada junto da ermida de São Brás, no perímetro das ruínas de Miróbriga. Testemunho emblemático, no plano regional, da política de valorização dos símbolos do poder público desenvolvida no reinado de $\mathrm{D}$. João $\mathrm{V}$, esta reconstrução do distintivo da autonomia concelhia assumiu deliberadamente, como uma referência de prestígio, a memória histórica da antiga urbe que antecedeu Santiago do Cacém.

ABSTRACT: In 1732 the municipality of Santiago do Cacém decided to rebuilt the old city's pillory, utilizing for that purpose the tige of a roman column located next to the Saint Blasius' chapel, within the limits of Mirobriga's ruins. Testimony of a policy of valuation of public symbols from the local government that began in the reign of John the Fifth, this reconstruction of the badge of the county's authonomy deliberatly used, as a reference of prestige, the historical memory of the ancient town which preceded Santiago do Cacém.

Conimbriga, 32-33 (1993-1994), 403-415 
(Página deixada propositadamente em branco) 


\section{UM EXEMPLO DO REAPROVEITAMENTO DE MATERIAIS ARQUEOLÓGICOS DE MIRÓBRIGA}

\section{A reutilização dos materiais de construção de Miróbriga}

À semelhança do que sucedeu com inúmeras outras ruínas de povoações do período romano 0), Miróbriga foi utilizada durante centúrias como pedreira. Consumado o seu abandono no século VI, devido a causas ainda não perfeitamente esclarecidas $\left({ }^{2}\right)$, e transferido o núcleo urbano

(') Acerca da constante histórica do reemprego de elementos arquitectónicos do passado em novas edificações, $\boldsymbol{c f r}$. as brilhantes observações de PETER ROCKWELL, Lavorare la Pietra. Manuale per VArcheologo, lo Storico dell'Arte e il Restauratore, versão italiana, Roma, 1989, pp. 17 e 201.

(2) V. J[ORGE] DE AlARCÃO, Roman Portugal, II, Gazetteer (Inventário), Warminster, 1988, p. 173, col. B:

"A data e razões do abandono de Miróbriga são, por enquanto, inteiramente desconhecidas; u capitel visigòtico prova todavia a sobrevivência da cidade neste período."

Existe controvérsia entre os investigadores, já desde o século XVIII, a respeito dos factores que deram azo ao declínio e posterior cessão de Miróbriga. Um motivo de certo peso foi, sem dúvida, a severa crise económica que se abateu sobre a região no século IV (KATHLEEN WARNER SLANE, "Miróbriga and its History", em Miróbriga. Investigations at an Iron Age and Roman Site in Southern Portugal by the University of Missouri-Columbia, 1981-1986, dir. por WILLIAM R. BIERS, Oxford, 1988, pp. 141 e 143, nota 10). Especulou-se também com a ocorrência, nessa centúria, de um sismo de grande magnitude que teria danificado consideravelmente o aglomerado urbano, levando à sua desocupação, mas ainda não se estudou com rigor esta questão. $\mathrm{O}$ mesmo podemos dizer no tocante ao impacto dos movimentos militares e populacionais dos séculos V e VI.

Conimbriga, 32-33 (1993-1994), 403-415 
para a colina a poente $\left({ }^{3}\right)$, tomou-se um sítio de fácil e pouco dispendioso abastecimento de materiais de construção, em particular de cantarias lavradas.

Segundo referiu D. Fernando de Almeida,

"Viveu, o povoado, com o seu santuário, uma vida de paz até à invasão dos Bárbaros: incendiada e arruinada, [Miróbriga] não voltou a ser habitada e caiu em ruínas. O templo de Esculápio, no cimo do monte, de boa construção, talvez tivesse sido aproveitado, na Idade Média, como atalaia. Entretanto, ia tudo servindo de pedreira para as necessidades dos vizinhos. Ùltimamente as suas pedras milenárias até têm sido transformadas em brita para as estradas [...]" $\left(^{(4)}\right.$.

Não se sabe exactamente quando começou a depredação das ruínas para o aproveitamento da sua pedraria. Os dados que temos vindo a coligir indicam que ela principiou logo na Baixa Antiguidade, continuou ao longo da época medieval e foi, depois, especialmente intensa durante os séculos XVI-XVIII.

Tal demanda persistiu, embora em menor escala, até às escavações sistemáticas promovidas, a partir de 1918, pelo Dr. João Gualberto da Cruz e Silva [Santiago do Cacém, 8 de Fevereiro de 1881 — Lisboa, 6 de Novembro de 1948], fundador e primeiro director do Museu Municipal de Santiago do Cacém $\left(^{5}\right)$. O trabalho deste investigador, pioneiro, difícil e incompreendido, contribuiu de forma decisiva para uma tomada de consciência pública a respeito da importância histórica da estação ( ${ }^{6}$ ). Foi graças a ele que se alcançou a classificação de uma área considerável do

(3) A[NTÓnio] de M[ACEDo] E S[ILVA], "O Castello de Santiago de Cacem”, em O Panorama, 2a . Série, II, Lisboa, 1843, p. 121; id., Annaes do Municipio de SanctYago de Cassem, Beja, 1866, p. 4; 2a. ed., Lisboa, 1869, pp. 9 e 14.

(4) D. Fernando DE Almeida, Ruinas de Miróbriga dos Célticos (Santiago do Cacém), Setúbal, 1964, p. 75.

(5) As conclusões das suas pesquisas em Miróbriga, truncadas pela morte, foram apenas parcialmente divulgadas: JoÃo [GUALBERTO DA CRUZ E] SILVA, "Concelho de S. Tiago de Cacem. Noticia Historica", em Album Alentejano. Apéndice a Provinda do Baixo Alentejo, dir. de Pedro Muralha, [Lisboa], [1937], pp. 1066-1067; id., "Apontamentos e Considerações sobre as Pesquisas Arqueológicas realizadas desde 1922 nos Concelhos de S. Tiago-de-Cacém, Sines e Odemira", em Arquivo de Beja, II, 1-2 e 3-4, Beja, 1945, pp. 131-134 e 291-299; III, 1-2, Beja, 1946, pp. 336-351. Cfr. D. FERNANDO DE ALMEIDA, op. cit., p. 8.

$\left.{ }^{6}\right)$ [ABEL VIANA], "Notas \& Nótulas. João Gualberto da Cruz e Silva", em Arquivo de Beja, V, 3-4, Beja, 1948, pp. 362, col. B-363, col. B. 
seu perímetro como Imóvel de Interesse Público, em $1940\left({ }^{7}\right)$ e $1943\left({ }^{8}\right)$, e, posteriormente, a aquisição da mesma por parte do Estado $\left({ }^{9}\right)$.

Nos montes e outras construções das herdades, courelas e quintas que circundam Miróbriga encontram-se numerosas peças daqui provenientes, reutilizadas em muros, soleiras e vergas de portas, calçadas, pias, etc. O mesmo sucede com diversos edifícios da cidade de Santiago do Cacém.

É interessante lembrar o que escreveu a este propósito Inácio de Vilhena Barbosa:

"Das ruinas de Miróbriga saíram, certamente, os materiaes para a edificação da villa de Santiago de Cacem." $\left.{ }^{10}\right)$.

Opinião seguida de perto por Augusto de Pinho Leal:

"A cidade de Merobriga não era no mesmo logar onde hoje vemos a florescente villa de S. Thiago de Cacem, mas no outeiro onde existem as ruinas do seu vetusto castello, onde se teem encontrado muitos vestigios de antigas construcções, e outros objectos que provam ter aqui existido uma povoação importante. Foi com os seus materiaes que se fundou a villa actual.” (n).

Estes materiais constituem uma parcela não pouco relevante do espólio da estação, pelo que a Real Sociedade Arqueológica Lusitana, tendo em vista o seu estudo e preservação, efectuou o inventário de todos os vestígios de que há referência e esforça-se por actualizá-lo periodicamente.

Existe também a preocupação de, sempre que na área referida se arruina ou é demolido um edifício, procurar fazer o acompanhamento dessa situação, com o intuito de acautelar a destruição ou o extravio de quaisquer elementos de interesse científico que possam eventualmente surgir.

Ao trabalho directo sobre o terreno acresce ainda o rastreio das diversas fontes documentais de natureza arquivística susceptíveis de fornecerem indícios acerca deste assunto e de outros temas relativos à investigação e à conservação de Miróbriga.

Os livros de actas das vereações da Câmara Municipal, que se conservam - com alguns hiatos — desde 1637 (12), indubitavelmente um

(7) Decreto-Lei n. ${ }^{\circ} .30$ 762, de 26 de Setembro de 1940.

(8) Decreto-Lei n. ${ }^{\circ} .32$ 973, de 18 de Agosto de 1943.

(9) D. FERNANDO DE ALMEIDA, op. cit., loc. cit.

(,0) I[NÁCIO] DE VILHena BARBOSA, As Cidades $\boldsymbol{e}$ Villas da Monarchia Portugueza que teem Brasão d'Armas, III, Lisboa, 1862, p. 28.

(n) Augusto Soares de Azevedo Barbosa De Pinho Leal, Portugal Antigo e Moderno, IX, Lisboa, 1880 [2a. ed fac-simil., Trafaria, 1990], p. 41, col. A.

$\left.{ }^{12}\right) \boldsymbol{V}$. JOÃO MADEIRA, "Fontes de História Contemporânea no Concelho de Santiago do Cacém: Contributo para o seu Conhecimento", em MARIA JosÉ DA SILVA LEAL 
acervo informativo de primeira ordem para a história do concelho, foram examinados com minúcia no âmbito da presente prospecção. Identificámos neste fundo dois documentos relativos a um interessante aspecto da questão em apreço: o emprego de uma coluna de Miróbriga para a reconstrução do pelourinho de Santiago do Cacém na primeira metade do século XVIII.

\section{O pelourinho setecentista de Santiago do Cacém}

$\mathrm{Na}$ sessão da vereação da Câmara, efectuada em 27 de Agosto de 1732, estando presentes o Doutor Francisco Coelho de Mello, juiz de fora, que presidiu, João Dias Parrado e Manuel Salema de Medeiros, vereadores, Estêvão da Rosa, procurador substituto, na ausência de Manuel de Frias Vieira, e João Rodrigues Beja, escrivão, deliberou-se proceder à substituição do antigo pelourinho, sito no meio da Praça da então vila, por se encontrar derrubado e ter as cantarias danificadas, e reerguê-lo junto às escadas do hospital do Espírito Santo, que delimita parcialmente o dito arruamento pelo lado norte.

Para servir de fuste (hástea) do monumento foi decidido mandar trazer uma pedra que jazia, semienterrada na relva e sem uso, perto da ermida de São Brás, entregando ao santo, ou seja, à fábrica do templo, a título de indemnização, um quarto de ouro. Deram-se igualmente instruções ao escrivão para fazer chamar um carreteiro a fim de transportar a dita pedra e alvanéus para edificarem o pelourinho. Tudo isto consta do acórdão da reunião, lançado no competente livro de actas por João Rodrigues Beja $\left({ }^{13}\right)$, que transcrevemos em apêndice documental sob o $\mathrm{n}^{\circ}$. I.

A citada peça aparece descrita no assento do seguinte modo: “[...] huma pedra grande redonda [...] em forma de coluna" $\left({ }^{14}\right)$. A ajuizar pela presente indicação, tratava-se certamente de um fuste monolítico.

Este documento contitui a primeira menção ao pelourinho antigo de que há notícia. Não se conhecem indícios seguros que permitam averiguar rigorosamente quando foi construído, mas admitimos que ascenda ao

\& Miriam HalPern Pereira (dir. de), Arquivo e Historiografia. Colóquio sobre as Fontes de História Contemporânea Portuguesa [Lisboa, 1984], Lisboa, 1988, p. 175.

(13) Santiago do Cacém, Arquivo Histórico Municipal, Livro de Actas das Vereações de 1732-1738, Livro Manuscrito s./n., fis. $48-48$ v. ${ }^{\circ}$.

(14) Id., ibid.

Conimbriga, 32-33 (1993-1994), 403-415 
reinado de D. Manuel I, à semelhança do que sucedeu com muitas outras localidades do país $\left({ }^{15}\right)$ - como é o caso da vizinha vila de Alvalade $\left({ }^{16}\right)$. Talvez até tenha substituído outro exemplar, medieval.

Santiago do Cacém atravessou, nos finais do século XV e nos primórdios do XVI, um surto de desenvolvimento, patente nos edifícios então reconstruídos (igreja paroquial de Santiago Maior, igreja e hospital do Espírito Santo) ou feitos de raiz (igreja da Santa Casa da Misericórdia). Os três últimos imóveis que referimos localizam-se na Praça, denominada então Rossio ou Campo de Santa Maria $\left({ }^{17}\right)$, verdadeiro foro cívico e centro da vida da povoação onde também ficavam os paços do concelho $\left({ }^{18}\right)$. A erecção do padrão municipal deve ter surgido nesse período de florescimento local que coincide com a urbanização do terreiro. Por outro lado, assinale-se que a terra possui o estatuto de vila desde, pelo menos, o tempo de D. Afonso III (19) e recebeu de D. Manuel um novo foral, dado em Santarém a 20 de Setembro de $1510\left({ }^{20}\right)$.

A implantação do pelourinho no meio da Praça, diante dos paços concelhios e na área mais nobre da povoação, é a habitual nestas circunstâncias $\left({ }^{21}\right)$. Daqui se podia avistar, de acordo com a tradição, a forca construída num outeiro fronteiriço que dela retirou o topónimo, o Cerro da Forca, onde ainda existem algumas pedras do supedáneo do aparelho de suplício. A remoção daquele monumento para junto do hospital deveu-se a que, no sítio em que estava, prejudicava a circulação, por ser o terreiro pequeno, como se diz no acórdão.

Vem a propósito sublinhar que o empenho da Câmara em reerguer muito condignamente o distintivo da sua autonomia prendeu-se decerto com a preocupação, amiúde afirmada no decurso do reinado de D. João V,

(15) Luís CHAVES, “Os Pelourinhos e os Cruzeiros”, em JOÃO BARREIRA (dir. de), Arte Portuguesa - As Artes Decorativas, I, Lisboa, s./d., p. 76.

$\left.{ }^{16}\right) C f r$. ÓMega [JoRge De OliveIRA], "O Pelourinho de Alvalade", em Nossa Terra, 3a. Série, I, 18, Santiago do Cacém, 13 de Março de 1932, p. 1, cols. A-C.

${ }^{(17)}$ Estes topónimos constam do provimento da visitação efectuada pela Ordem de Santiago, em 1518, a Santiago do Cacém (Lisboa, Arquivo Nacional da Torre do Tombo, Conventos Diversos - Ordem de Santiago, B-51-266, fis. [22-25 v. ${ }^{\circ}$.] e [32]).

$\left.{ }^{18}\right)$ António De Macedo E Silva, Annaes do Municipio de Sanct-Yago de Cassem, cit., 2a. ed., p. 121.

(19) Id., Annaes do Municipio de Sanct-Yago de Cassem, cit., pp. 15 e 46; 2a. ed., pp. $17-18$ e 74 .

$\left.{ }^{(20}\right)$ Id., Annaes do Municipio de Sanct-Yago de Cassem, cit., pp. 56-72; 2a. ed., pp. 84-89.

(21) Luís CHAVES, op. cit., pp. 76, col. B-77, col. B.

Conimbriga, 32-33 (1993-1994), 403-415 
de prestigiar os símbolos do poder público, testemunhos evidentes de um estado em gestação ${ }^{(22}$ ). Para além de urna simples beneficiação da vila, eremos que se poderá discernir neste acto o desejo de recuperação e valorização do sinal de jurisdição concelhia por excelência. Foi também pela mesma época que a autarquia começou a desenvolver esforços no sentido de se construir um novo edifício para albergar os seus paços, já que as antigas casas estavam incapazes de servir para as vereações e demais actos administrativos, o que todavia só se concretizou em 1781 (23).

É interessante advertir que a Câmara estava bem a par de que as ruínas visíveis nas imediações de São Brás pertenciam a uma antiga localidade, embora sem lhe conferir nome. No acórdão lê-se textualmente, pela nítida caligrafia de João Rodrigues Beja: "[...] huma Çidade, que se diz hauia naquelle sitio, que se aruinou" $\left({ }^{24}\right)$.

Desde há muito que os restos arqueológicos existentes na zona eram conhecidos. André de Resende examinou-os com atenção, identificou-os como pertencendo à Miróbriga de que tratou Plínio $\left({ }^{25}\right)$ e dedicou-lhes algumas páginas no tomo IV da sua obra De Antiquitatibus Lusitanice (26). $\mathrm{Na}$ senda do humanista eborense outros estudiosos se deslocaram a Santiago do Cacém para os observarem. Algo mais de uma década antes da data do documento que nos ocupa veio aqui propositadamente o $\mathrm{I}^{\circ}$. marquês de Abrantes, D. Rodrigo Anes de Sá Almeida e Menezes, o qual deu conta dos resultados da sua visita à Academia Real da História Portuguesa, na conferência de 31 de Julho de 1721 (27).

A disposição da edilidade em reaproveitar o fuste trazido de Miróbriga pode ser vista à luz desta consciência sobre a importância histórica da desaparecida povoação. Se era pragmático utilizar uma pedra que se prestava para o efeito e permanecia abandonada, parece-nos que existiu

(22) Cfr. JjosÉ] S[armento DE] M[ATos], "Arquitectura Civil", 5. u., em José Fernandes Pereira (dir. de) \& Paulo Pereira (coord, de), Dicionário da Arte Barroca em Portugal, Lisboa, 1989, p. 41, col. A.

(23) António de Macedo e SiLva, Annaes do Municipio de Sanct-Yago de Cassem, cit., 2a. ed., p. 121.

(24) Livro de Actas das Vereações de 1732-1738, cit., fl. 48 v. ${ }^{\circ}$.

(25) Plínio, O Velho, Naturalis Historia, IV, 116.

(26) ANDRÉ De ReSENDE, De Antiquitatibus Lusitaniœe, Évora, 1593, fl. 188.

(27) Colleçam dos Documentos, Estatutos, e Memorias da Academia Real da Historia Portugueza, í, Lisboa, 1721, pp. [333-335]; Manuel Telles da Sylva (MaRQUês DE ALeGrete), Historia da Real Academia da Historia Portugueza, I, Lisboa, 1727, pp. 300-302. 
igualmente da parte das autoridades concelhias a intenção de realçar a presença efectiva e simbolica do pelourinho, integrando nele uma peça da Antiguidade. Trata-se, pois, de uma alusão prestigiante à memoria do núcleo urbano que antecedeu Santiago do Cacém no tempo: um testemunho privilegiado do seu passado multissecular. Note-se que o edifício do hospital possuía também, aplicada na fachada principal, pelo menos desde o século XVI, a célebre inscrição consagrada a Esculápio (CIL II21 = ILS $6903=$ ILER $188=$ IRCP 144), proveniente de Miróbriga.

Talvez porque se levantassem dúvidas a respeito da propriedade efectiva da pedra, a Câmara cuidou de registar que esta se encontrava derrelicta, sem serventia, e que jamais pertencera a um cruzeiro, fazendo expressamente constar "antes ter sido tirada, segundo tradiçam, de Edefíçio antigo" das ruínas ${ }^{28}$ ). Com o escrúpulo de, ainda assim, não prejudicar São Brás, acordou-se oferecer à fábrica da ermida um quarto de ouro, como vimos.

O transporte do fuste fez-se segundo o previsto, uma vez que em sessão de 22 de Julho de 1733, comparecendo Manuel Fernandes Revolto, vereador mais velho que serviu de juiz por estar ausente da terra o Doutor Francisco Coelho de Mello, Manuel Salema de Medeiros e Francisco Louzeiro Zuzarte, vereadores, Manuel de Frias Vieira, procurador, e João Rodrigues Beja, escrivão, o procurador comunicou que o tesoureiro de São Brás não queria aceitar a esmola e propôs que a mesma se tomasse em depósito. A vereação determinou então que o quarto de ouro ficasse consignado em poder de Manuel de Frias Vieira, o qual se deu logo por entregue dele, conforme se regista no acórdão da reunião [documento $n^{\circ}$. II]. É possível que a deslocação da pedra não tivesse agradado aos responsáveis pela administração da ermida ou houvesse qualquer desentendimento quanto ao valor da mesma e que tal motivasse a resistência do tesoureiro em receber a dita importância.

Depois desta data perdemos o rasto do pelourinho. Não aparecem mais indicações a seu respeito na documentação camarária. Por estranho que isso nos possa afigurar-se, tão-pouco os estudos monográficos sobre Santiago do Cacém, a começar pelas Memórias sobre a Antiga Miróbriga, de Bernardo Falcão, sempre muito atento à arqueologia local e perfeito conhecedor da vida da terra no período setecentista, lhe dedicam uma só linha.

(28) Livro de Actas das Vereações de 1732-1738, cit., loc. cit.

Conimbriga, 32-33 (1993-1994), 403-415 


\section{Um paralelo regional: o pelourinho de Setúbal}

Há notícia de mais alguns casos de reutilização de colunas e outros elementos arquitectónicos da Antiguidade em pelourinhos. Um espécime elucidativo, situado em zona não muito distante de Santiago do Cacém, é o existente na cidade de Setúbal.

$\mathrm{Na}$ sequência da condenação, em 1759, do $8^{\circ}$. duque de Aveiro,

D. José de Mascarenhas, a quem pertencia a jurisdição desta terra, ainda com o estatuto de vila $\left({ }^{29}\right)$, o seu pelourinho foi demolido. Alguns anos mais tarde, o marquês do Pombal ordenou que se erigisse um novo padrão, à custa da Câmara. Ficaram incumbidos dessa tarefa José Bruno de Cabedo, coronel do Regimento e governador da Praça, nomeado director das obras públicas de Setúbal, e João Vasco Manoel de Braun, sargentomor da mesma, engenheiro e comandante de artilharia $\left({ }^{30}\right)$.

Ciente de que permanecia esquecida num recanto da povoação uma notável coluna corintia encontrada nas ruínas de Tróia durante as escavações que aí mandou fazer, em 1746, a princesa da Beira, D. Maria (depois D. Maria I)( $\left.{ }^{31}\right)$, Cabedo apreciou muito o valor patrimonial desta peça e decidiu reaproveitá-la na obra do pelourinho como o elemento de maior destaque. Assinale-se que a Herdade de Tróia pertencia, ao tempo, à freguesia de Melides, uma das nove que formavam o termo de Santiago do Cacém $\left({ }^{32}\right)$.

António Inácio Marques da Costa descreveu com pormenor as circunstâncias em que se verificou a condução da coluna e a sua aplicação:

"Um dos objectos mais notáveis que se encontraram nas excavações mandadas fazer pela princesa foi a bela coluna corintia que ela mandou que se erigisse em uma praça de Setúbal. Nessa ocasião o antigo pelourinho estava onde é agora o Largo da Ribeira (hoje do D. ${ }^{\text {or }}$ Francisco Soveral) e nele se ostentava a cruz da Ordem de Santiago, pois Setúbal era uma das comendas desta ordem, cujo exercício pertencia ao Duque de Aveiro.

(29) V. I[NÁCIO] DE VILHENA BARBOSA, op. dt., p. 50.

(30) Augusto Soares de Azevedo Barbosa de Pinho Leal, op. cit., p. 279, col. B.

(31) Vítor dos Santos Gonçalves, "Arronches Junqueiro e Tróia de Setúbal", em Arquivo de Beja, XXII, Beja, 1965, p. 168.

(32) Bernardo FalCÃo, Memórias sobre a Antiga Miróbriga (Lisboa, Biblioteca particular do Prof. Doutor Eng. ${ }^{\circ}$. Manuel António Falcão Beja da Costa, ms. s./n.), fl. 14; ANTÓNIO De MaCedo E SILVA, Annaes do Municipio de Sanct-Yago de Cassem, cit., p. $75 ; 2^{\text {a }}$. ed., p. 61.

Conimbriga, 32-33 (1993-1994), 403-415 
A ordem da princesa foi em parte cumprida, erigindo-se a coluna à entrada da Rua dos Sapateiros que se fazia pela Porta Nova; como porém neste lugar embaraçava o trânsito das seges, foi dali tirada e dada aos frades do Espírito Santo, para estes a elevarem no largo defronte do seu convento à Fonte Nova. Aí esteve prostrada alguns anos, mas fazendo nesse lugar ainda obstáculo às corridas eqüestres por ocasião dos festejos, foi enterrada no mesmo largo.

Sendo demolido o pelourinho antigo da Praça da Ribeira, que representava a jurisdição do Duque de Aveiro, foi pelo Marquês de Pombal ordenada a construção de outro pelourinho em outra praça.

Foi então que o engenheiro Cabedo encarregado da obra, sendo informado da existência da bela coluna corintia, a mandou exumar para a erigir como pelourinho na Praça de S. Pedro (que hoje tem o nome do Marquês de Pombal), à qual a dita coluna serve de elegante ornamento." ( $\left.{ }^{33}\right)$.

O monumento setubalense, algo mais tardio do que o seu congénere de Santiago do Cacém (e talvez até inspirado neste), atesta a estima concedida à coluna romana aí aplicada, não só como obra de arte mas também como autêntica marca falante de uenustas e de nobilitas — ou seja, uma exaltação/projecção das raízes históricas da região.

\section{O pelourinho novo de Santiago do Cacém}

O terremoto do dia de Todos-os-Santos de 1755 causou estragos muito avultados em Santiago do Cacé( $\left.{ }^{34}\right)$. À semelhança de tantos outros edifícios da vila, o hospital do Espírito Santo foi gravemente afectado e ruiu em parte ${ }^{(35)}$. O pelourinho deve ter sofrido também danos apreciáveis nesta ocasião e julgamos muito plausível que, inclusivamente, se quebrasse o respectivo fuste. Quando a Santa Casa da Misericórdia, sob a provedoria de Bernardo Falcão, reconstruiu o hospital, em 1781, não se voltou a colocá-lo na posição que ocupava. É mesmo provável que os seus fragmentos tenham sido aproveitados em obras de reconstrução ou permaneçam

(33) A[NTónio] I[NÁcio] Marques da Costa, "Estudos sobre Algumas Estações da Época Luso-Romana nos Arredores de Setúbal”, em O Archeologo Português, XXIX, Lisboa, 1933 [1934], pp. 19-20.

(34) Lisboa, Arquivo Nacional da Torre do Tombo, Dicionário Geográfico de Portugal, IX, n. ${ }^{\circ} 187$ [Memória Paroquial de Santiago do Cacém, da autoria do Prior Manuel Coelho de Sampayo e Távora], fis. 1215 v. ${ }^{\circ}$ e 1220; BERNARDO FALCÃO, op. cit., fis. 21 e 24 v. ${ }^{\circ}$.; ANTónio de Macedo E Silva, Annaes do Municipio de SanctYago de Cassem, cit., p. 91; 2a ed., p. 57.

(35) BERNARdo FALCão, op. cit., fl. 24 v. ${ }^{\circ}$

\section{Conimbriga, 32-33 (1993-1994), 403-415}


debaixo dos escombros terraplanados para a nova edificação do estabelecimento assistencial.

Apesar deste percalço, a tradição da localização do pelourinho na Praça não se perdeu e, já adiantado o século XIX, a Câmara deliberou recuperá-la. Em 1844 consertou-se a feitura de um novo monumento, pelo preço de $76 \$ 800$ réis, com o oficial de canteiro José Miguel Rodrigues. Foi instalado no seu sítio em 1 de Junho de 1845, importando esta obra em $16 \$ 800$ réis, além do transporte desde a pedreira ${ }^{36}$. Aí permaneceu ele até aos nossos dias $\left({ }^{37}\right)$.

\section{APÊNDICE DOCUMENTAL}

1732, Agosto, 27. Santiago do Cacém. Acórdão da Câmara para a reconstrução do pelourinho junto às escadas do hospital do Espírito Santo, na Praça da vila, aproveitando-se para o efeito uma coluna existente perto da ermida de São Brás e dando o procurador do concelho ao santo um quarto de ouro, a título de indemnização.

Santiago do Cacém, Arquivo Histórico Municipal, Livro de Actas das Vereações de 1732-1738, Livro Manuscrito s./n., fis. 48-48 vº.

"Acordaram em camera, que uisto o pelou/rinho estar derrubado, e as pedras todas que/bradas, e incapazes de seruirem, se fizese / de nouo tirando se do meyo da praça por ser / pequena, e se puzese para hum lado iunto / as escadas do hospital, onde ficaua em boa / porporçam: e que iunto a Sam Bras na Rel/ua se achaua huma pedra grande redonda // REdonda em forma de columna, emterrada / no cham sem prestimo algum, e inútil para / outro ministerio, e que bem mostraua não ter / seruentia para outra couza senam para a / hastea do Pelourinho, e nunca seruir de cru/zeiro, nem ter forma para isso, mas antes / ter sido tirada, segundo tradiçam, de Ede/fiçio antigo de huma Çidade, que se dis ha/uia naquelle sitio, que se aruinou: pello que / ditreminaram que a dita pedra se mandas/se buscar, e se puzese no pelourinho, e que eu / Escriuam <mandace> notificar carreteiro para a ir buscar, / e ofiçiaes para fazerem o dito pelourinho / todo de nouo no sitio mençionado, pondo se / promptos todos os materiaes tudo á custa do / Conselho: e que o Procurador do Conselho / dese hum quarto de ouro de esmola ao sancto / visto a pedra estar diante da sua Jgreja / na Relua sem embargo de se naõ saber da / seruentia da dita pedra; e asignaram: //"

(36) António de Macedo E Silva, Annaes do Municipio de Sanct-Yago de Cassem, cit., $2^{\text {a. }}$ ed., p. 146.

${ }^{(37)}$ De início esteve colocado perto da casa solarenga dos Condes do Braciai. Nos primórdios do século XX transitou para o centro da Praça.

Conimbriga, 32-33 (1993-1994), 403-415 
II

1733, Julho, 22. Santiago do Cacém. Acórdão da Câmara para que, visto o tesoureiro da ermida de São Brás não querer receber o quarto de ouro que se mandou dar ao santo como indemnização por uma coluna que se levou das imediações do mesmo templo para a reconstrução do pelourinho, o procurador do concelho conserve em seu poder tal importância, na qualidade de fiel depositório.

Santiago do Cacém, Arquivo Histórico Municipal, Livro de Actas das Vereações de 1732-1738, Livro Manuscrito s./n., fl. 49.

"Na dita Camera requereu o dito Pro/curador, que o Thezoureiro de Sam Bras / naõ queria aseitar o quarto de ouro, que / tinham mandado dar de esmola ao / Sancto a respeito da pedra, que ueo pera / o pelourinho, e que se puzese em de/pozito, os ditos Offiçiaes da Camara man/daram ficase depozitado na mam do di/to Procurador para a todo o tempo dar / conta delle, e se deu por emtregue, e asignou. //" 